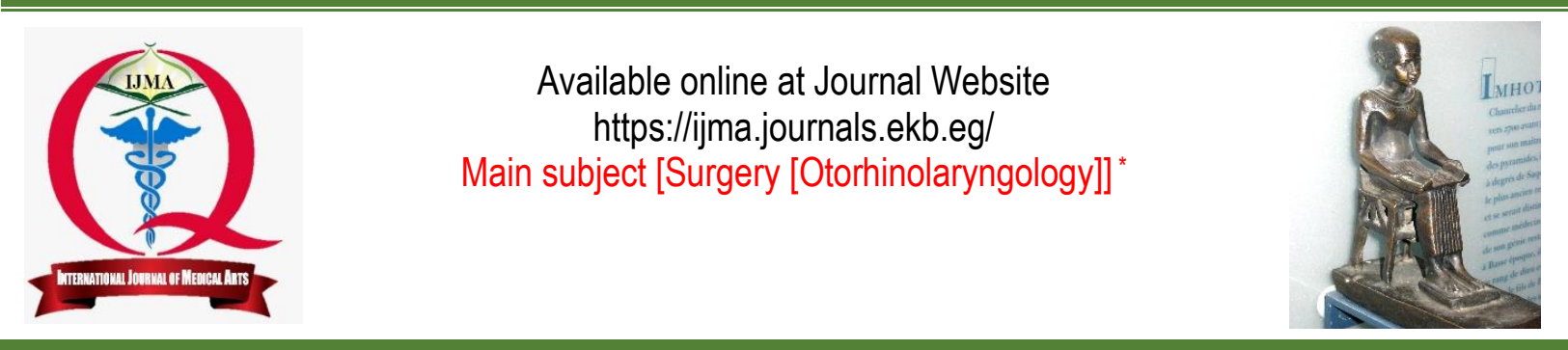

Original article

\title{
Comparative Study between Subannular T- Tube and Repetitive Transtympanic T-Tube Technique
}

\author{
Mohamed Eldabaa ${ }^{\mathbf{a}}$; Ahmed Ibrahim Zaghloul ${ }^{\mathbf{b}}$; Ahmed Fayez Ahmed ${ }^{\mathbf{b}}$
}

Department of Otorhinolaryngology, Faculty of Medicine, Al-Azhar University, Egypt[a].

Department of Otorhinolaryngology, Damietta Faculty of Medicine, Al-Azhar University, Egypt ${ }^{[b]}$.

Corresponding author: Ahmed Fayez Ahmed

Email:dr.ahmedfayez@yahoo.com

Received at: January 20, 2020; Revised at: March 9, 2020; Accepted at: March 11, 2020; Available online at: March 11, 2020

DOI: 10.21608/ijma.2020.20873.1085

ABSTRACT

Background: Otitis media $[\mathrm{OM}]$ is the second most common disease of childhood after upper respiratory tract infection. There was no consensus on the ideal treatment modality yet.

Aim of the work: To compare the use of trans-tympanic T tube [TTTT] and subannular T tube [SATT] in recurrent otitis media, recurrent otitis media with effusion or tympanic membrane retraction.

Patients and Methods: This is a prospective controlled study, which was conducted at Al-Azhar university hospital [Damietta]. It included 40 patients that were randomly divided into two groups A and B: Group A: include 20 patients who were submitted to trans-tympanic T-tube. Group B included 20 patients who were submitted to sub annular T-tube. Patient data and outcome were documented and compared.

Results: The duration that TTTTs and SATTs remained in place ranged from 4 to 19 months with a mean of 10.62 and there was a significant decrease of duration in TTTT in comparison to SATT groups [7.28 vs 14.80 respectively]. Besides, in 14 cases in the SATT group, the tube is still in place. Extrusion was reported in 10 cases [ 8 in the TTTT group and 2 in the SATT group] and finally removal was reported in 6 patients [2 in TTTT group and 4 in the SATT group.

Conclusion: The use of SATTs for long term middle ear ventilation is safe and more efficient than V-T Grommet TTTTs for maintaining middle ear ventilation and prevention of recurrent interventions in children with less otorrhea and plugged tubes.

Keywords: Subannular; Repetitive transtympanic; T-tube; Otitis media; Eustachian tube dysfunction.

This is an open access article under the Creative Commons license [CC BY] [https://creativecommons.org/licenses/by/2.0/]

Please cite this article as: Eldabaa M, Zaghloul Al, Ahmed AF. Comparative Study between Subannular T- Tube and Repetitive Transtympanic T-Tube Technique. IJMA 2020; 2[2]: 351- 357.

* Main subject and any subcategories have been classified according to researchers' main field of study. 


\section{INTRODUCTION}

A normally functioning eustachian tube allows pressure regulation of the middle ear and protection from the nasopharynx. Abnormal function of the eustachian tube has been implicated as one of the most important factors in the pathogenesis of all middle ear disease. The placement of tympanostomy tubes provides an alternative means of middle ear ventilation during periods of eustachian tube dysfunction [1]. Patients who develop recurrent acute otitis media and otitis media with effusion or experience Eustachian tube dysfunction with tympanic membrane retraction require short to long term ventilation of the middle ear. These patients undergo different procedures to achieve that ventilation, such as placement of Transtympanic Ttube, or Subannular T-tube[2]. The subannular technique initially illustrated by Eisner and Alexander in 1960 and described by Simonton and has been used by other practitioners ${ }^{[3]}$.

One of the main reasons for the extrusion of tympanostomy tubes is the centrifugal migration of the tympanic membrane epithelium towards the ear canal. Placement of a tube beneath the annulus reduces the effect of these migratory forces and enables the tube to remain in situ for a longer time. The subangular ventilation tube prolongs the intubation time of the middle ear without a need for replacement, almost as simple to insert as the transtympanic tube and leaves the tympanic membrane intact [4]. Subannular tubes have been used in intractable middle ear effusion, severe myringosclerosis, posterior tympanic membrane collapse, tympanic membrane adhesion, and atelectasis ${ }^{[5]}$.

\section{AIM OF THE WORK}

Our aim in this study is to compare the use of transtympanic $\mathrm{T}$ tube [TTT] and subannular $\mathrm{T}$ tube [SAT] in cases of recurrent otitis media, recurrent otitis media with effusion or tympanic membrane retraction.

\section{PATIENTS AND METHODS}

This study included patients with recurrent otitis media with effusion, recurrent acute otitis media, tympanic membrane retraction. They were presented to the ENT department of Al-Azhar University Hospital [New Damietta]. The duration of the study was from January 2019 up to November
2019. Patients were assigned into one of two groups: Group [1] included 20 patients, treated by a transtympanic ventilation tube. Group [2] included 20 patients, treated by subannular ventilation tube.

Informed consent was taken from all patients, and study protocol was approved by the local institutional review board of Damietta Faculty of Medicine, AlAzhar University [IRP code: 18-02-001].

Diagnosis of the disease was established by clinical, otoscopic, endoscopic, microscopic and audiological investigation. All patients were studied prospectively.

Preoperative full history taking, ENT examination, general examination, laboratory, and audiological investigations were done for all the patients. Surgery was carried out; operative details were recorded and postoperative follow up was done for studied cases.

Pure tone audiometry, tympanometry, speech audiometry, and acoustic reflex were the main bundle of audiological investigations.

Surgical technique: All operations were completed under general anesthesia.

Transtympanic Tube Technique: Using an otoendoscope, a radial incision was made in the anteroinferior quadrant with a myringotomy knife. The middle ear effusion was aspirated with a microsuction tube before inserting the transtympanic $\mathrm{T}$ Tube. A ventilation tube T-tube [length, $12 \mathrm{~mm}$; internal diameter, $1.14 \mathrm{~mm}$ ]; Medtronic Xomed, Inc] was picked up with a crocodile forceps and introduced into the ear canal. The tube was rotated through the myringotomy incision.

Subannular Tube Technique: Using an otoendoscope, a tympanometry flap was elevated from the posterior auditory canal wall $5 \mathrm{~mm}$ from the annulus, exposing the middle ear. Any fluid in the cavity was suctioned and adhesions to the promontory were removed.

A ventilation subannular T-Tube [SAT]: 3 [T-tube [length, $12 \mathrm{~mm}$; internal diameter, $1.14 \mathrm{~mm}$; Medtronic Xomed, Inc] was inserted in the posteroinferior part of the middle ear under the external auditory canal tympanometry flap. While the two prongs of the tube were in the middle ear, the flap was placed over the tube, leaving only its tip exposed in the canal. 
Postoperative care: The patient can go back home after one day. Antibiotics, decongestant nasal drops, mucolytic and analgesics were prescribed. Water is kept away from the ear during bathing by using earplugs or a piece of cotton soaked with Vaseline. Clinical evaluation for follow up was performed at regular visits until extrusion or removal occurs.

Assuring tube function: The proper function of ventilation tube if it was seen to span the eardrum, if its lumen is unobstructed and if no middle ear effusion is present. When tube function cannot be confirmed by visual inspection, pneumatic otoscopy and tympanometry were done. If the TM was immobile and translucent on pneumatic otoscopy with no other signs of middle ear effusion, the tube was functioning probably.

A flat [type B] tympanogram: with a large volume measurement and normal hearing confirm that the external and middle ears are connected by a functioning tube. A flat tympanogram with small volume indicates a nonfunctioning tube with middle ear effusion

Postoperative complications: Periodic follow up of the patients was done to detect and manage postoperative complications which include:

Post-operative otorrhea: Post-operative otorrhea occurs in $5 \%$ of cases who undergoes the SAT and in $10 \%$ inpatient who undergoes transtympanic $\mathrm{T}$ Tube [TTTT] within the first few weeks and more frequent in children with tubes inserted to control recurrent acute infection.

Management of post-VT otorrhea includes systemic antibiotics with B-lactamase coverage, topical antibiotics that contain neomycin, polymyxin, and hydrocortisone. Aural toilet with suction or dry mopping is essential to remove debris and allow entry of ear drops.

Blocked ventilation tube: postoperative blockage occur in $10 \%$ of cases causing the tube to become ineffective. The blockage occurs in the early postoperative period and associated with transient otorrhea. Treatments include a course of eardrops a combination of antibiotic/steroids, suctioning and/or debridement with or without an ear pick using microscopic guidance.

Residual perforation: Residual perforation occurs in $5 \%$ of cases. Permanent perforation is one of the most serious complications of VT insertion because it requires additional surgery, 6 months is considered the cutoff for the definition of a permanent perforation.

Statistical analysis: Data were analyzed using Statistical Program for Social Science [SPSS] version 15.0. Quantitative data were expressed as mean \pm standard deviation [SD]. Qualitative data were expressed as frequency and percentage. Independent-samples t-test of significance was used when comparing two means for normally distributed data. Mann-Whitney U test: was used when comparing two means [for abnormally distributed data]. Chi-square test: was used when comparing non-parametric data. $P$-value $<0.05$ was considered significant.

\section{RESULTS}

The demographic data of our studied populations was illustrated in table [1]. As shown in table [2], there was no statistically significant difference [pvalue $>0.05$ ] between studied groups as regard outcome. However, there was increase in number of patients where the tube still in place in SATT group [70\%] than TTTT group [50.0\%] but the difference did not reach statistical significance. The tube was removed for 2 patients in TTTT group and for 4 patients in SATT group, while extrusion was reported in 8 patients [40.0\%] in TTTT group and 2 patients [10.0\%] in SATT group.

Tables [3 and 4] showed a statistically significant difference between pre- and post-operative air bone gap $[A B G]$ in both groups. However, no difference was found regarding complications.

In table [5], there was a highly statistically significant difference [p-value $<0.001$ ] between studied groups as regards $A B G$. It was significantly increased in TTTT when compared to SATT groups [16.3 \pm 3.9 vs $5.3 \pm 1.9$ respectively]. 
Table [1]: Comparison between studied groups regarding demographic data.

\begin{tabular}{|c|c|c|c|c|c|c|c|}
\hline \multicolumn{2}{|c|}{ Demographic data } & \multicolumn{2}{|c|}{$\begin{array}{r}\text { Group1 [TTTT } \\
{[[\mathrm{N}=20}\end{array}$} & \multicolumn{2}{|c|}{$\begin{array}{r}\text { [Group } 2 \text { [SATT } \\
{[\text { [ } \mathrm{N}=20}\end{array}$} & Stat. test & P-value \\
\hline \multirow[t]{3}{*}{ [Age [years } & Mean $\pm S D$ & \multicolumn{2}{|c|}{$8 \pm 2.4$} & \multicolumn{2}{|c|}{$11.4 \pm 7.2$} & \multirow[t]{2}{*}{$M W=131.5$} & 0.063 \\
\hline & Median & \multicolumn{2}{|c|}{7.5} & \multicolumn{2}{|c|}{8} & & NS \\
\hline & Range & \multicolumn{2}{|c|}{$5-15$} & \multicolumn{2}{|c|}{$6-30$} & & \\
\hline \multirow[t]{2}{*}{ Sex } & Male & 12 & $60 \%$ & 11 & $55 \%$ & \multirow[t]{2}{*}{$X^{2}=0.1$} & \multirow{2}{*}{$\begin{array}{r}0.749 \\
\text { NS }\end{array}$} \\
\hline & Female & 8 & $40 \%$ & 9 & $45 \%$ & & \\
\hline
\end{tabular}

MW: Mann-Whitney Test. $X^{2}$ : Chi-square test; $N S$ : $p$-value $>0.5$ is considered non-significant.

Table [2]: Comparison between studied groups as regard outcome.

\begin{tabular}{|l|l|c|c|c|c|c|c|}
\hline \multicolumn{2}{|c|}{ Outcome } & \multicolumn{2}{c|}{$\begin{array}{c}\text { TTTT } \\
{[N=20]}\end{array}$} & \multicolumn{2}{c|}{$\begin{array}{c}\text { SATT } \\
{[N=20]}\end{array}$} & Stat. test & P-value \\
\hline \multirow{3}{*}{ Outcome } & Still & 10 & $50 \%$ & 14 & $70 \%$ & \multirow{2}{*}{$\mathrm{X}^{2}=4.93$} & $\begin{array}{c}0.084 \\
\text { NS }\end{array}$ \\
\cline { 2 - 6 } & Removed & 2 & $10 \%$ & 4 & $20 \%$ & & \\
\cline { 2 - 6 } & Extrusion & 8 & $40 \%$ & 2 & $10 \%$ & & \\
\hline
\end{tabular}

$\mathrm{X}^{2}$ : Chi-square test NS: $\mathrm{p}$-value $>0.5$ is considered non-significant.

Table [3]: Comparison between studied groups as regard complications.

\begin{tabular}{|c|c|c|c|c|c|c|c|}
\hline & Complications & \multicolumn{2}{|c|}{$\begin{array}{c}\text { TTTT } \\
{[\mathrm{N}=20]}\end{array}$} & \multicolumn{2}{|c|}{$\begin{array}{c}\text { SATT } \\
{[N=20]}\end{array}$} & Stat. test & P-value \\
\hline \multirow{8}{*}{ 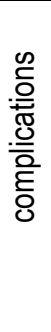 } & No & 10 & $50 \%$ & 15 & $75 \%$ & \multirow{8}{*}{$X^{2}=7.9$} & \multirow{8}{*}{$\begin{array}{c}0.245 \\
\text { NS }\end{array}$} \\
\hline & New OME & 5 & $25 \%$ & 1 & $5 \%$ & & \\
\hline & Block by cerumen & 2 & $10 \%$ & 1 & $5 \%$ & & \\
\hline & Otorrhea & 2 & $10 \%$ & 1 & $5 \%$ & & \\
\hline & new atelectatic & 1 & $5 \%$ & 0 & $0 \%$ & & \\
\hline & residual perforation & 0 & $0 \%$ & 1 & $5 \%$ & & \\
\hline & Block by granulation tissue & 0 & $0 \%$ & 1 & $5 \%$ & & \\
\hline & Cholesteatoma & 0 & $0 \%$ & 0 & $0 \%$ & & \\
\hline
\end{tabular}

$\mathrm{X}^{2}$ : Chi-square test; NS: $\mathrm{p}$-value $>0.5$ is considered non-significant.

Table [4]: Comparison between ABG [pre \& post] in group 1 and group 2.

\begin{tabular}{|c|c|c|c|c|c|}
\hline \multicolumn{2}{|l|}{$A B G$} & $\begin{array}{c}\text { Pre } \\
{[N=20]}\end{array}$ & $\begin{array}{c}\text { Post } \\
{[N=20]}\end{array}$ & Stat. test & P-value \\
\hline \multirow{2}{*}{$\begin{array}{l}\text { Group 1 } \\
\text { [ [TTTT }\end{array}$} & Mean & 29.5 & 16.3 & \multirow[t]{2}{*}{$t=9.9$} & $<0.001$ \\
\hline & $\pm S D$ & 4.5 & 3.9 & & HS \\
\hline \multirow{2}{*}{$\begin{array}{l}\text { Group } 2 \\
\text { [[SATT }\end{array}$} & Mean & 24.3 & 5.3 & \multirow[t]{2}{*}{$t=16.5$} & $<0.001$ \\
\hline & $\pm S D$ & 4.8 & 1.9 & & HS \\
\hline
\end{tabular}

$t$ : independent sample T test; HS: $p$-value $<0.001$ is considered highly significant.

Table [5]: Comparison between studied groups as regards postoperative ABG.

\begin{tabular}{|l|l|c|c|c|c|}
\hline \multicolumn{2}{|l|}{ Post-operative ABG } & $\begin{array}{c}{[\text { Group1 [TTTT }} \\
{[\mathrm{N}=20]}\end{array}$ & $\begin{array}{c}{[\text { Group2 [SATT }} \\
{[\mathrm{N}=20]}\end{array}$ & Stat. test & P-value \\
\hline \multirow{2}{*}{ PO ABG } & Mean & 16.3 & 5.3 & $\mathrm{~T}=11.3$ & $\begin{array}{c}<0.001 \\
\text { HS }\end{array}$ \\
\cline { 2 - 4 } & ISD & 3.9 & 1.9 & & \\
\hline
\end{tabular}

$t$ : independent sample T test; $\mathrm{HS}$ : $p$-value $<0.001$ is considered highly significant.

\section{DISCUSSION}

This is a prospective controlled study, which was conducted at Damietta university hospital, Al-Azher University, and included 40 patients who were randomly divided into two groups $A$ and $B$ : Group $A$ : include 20 patients underwent trans-tympanic T-tube [TTTT]. Group B: include 20 patients underwent subannular T-tube [SATT].
In this study, patients in the SATT group were older than those in the TTTT group [mean age $11.4 \pm 7.2$ vs $8 \pm 2.4$ respectively]. This coincides with Issam et al. ${ }^{[6]}$ who performed 4 years of follow-up of [216] TTTTs and [234] SATT [mean age $3.2 \pm 0.1 \mathrm{vs}$ $7.4 \pm 0.2$ respectively] although the actual age is different between the current one and their study, but their patients in SATT group were older. Besides, Daudi et al.[1] reported that a total of 57 tubes were 
placed in 45 patients: 27 [60\%] males and 18 [40\%] females. Patients' mean age at surgery was 23 years [range, 9 to 64 years]. The results of the present study are consistent with them as regards male predominance, but their patients were older than those of the present work.

Rosenfeld et al. ${ }^{[7]}$ reported that the most common indication for ear tube insertion remains persistent [ $>$ 3 months] otitis media with effusion [OME], or serous otitis media [SOM], that does not resolve after 3 months of clinical observation or does not improve with medical therapy. Additional indications for prompt ear tube insertion include complications of acute otitis media [AOM], such as meningitis, facial nerve palsy, and mastoiditis. In patients with these complications, ear tubes can help halt tympanic membrane injury [eg, from retraction pockets which distort the eardrum, and the subtle process of adhesive otitis media which limits ossicular vibrations and can lead to a permanent hearing loss]. Prompt insertion of tympanostomy tubes ventilates the middle ear space and prevents further retraction of an eardrum under the negative pressure.

As regard to associated comorbidity in this study, adenoids were reported in 14 patients. Previous ear surgery [grommet] was reported in 19 patients, while recurrent otitis media was reported in all patients. Zou et al. ${ }^{[8]}$ reported that adhesive otitis media is regarded as a later stage or sequelae and complication of all types of otitis media. In the clinic, late-stage OME often seen to progress to adhesive otitis media. Besides, Selvan and Karuppasamy[9] reported that the commonest etiology for adhesive otitis media in their study was allergy [35.5\%] followed by smoking [16.1\%]. These differences may be attributed to different locations of the studies.

In this study, TTTTS and SATTs were indicated in recurrent acute OM [8 cases] and OME [19 cases], tympanic membrane retraction [11 cases] and nonrepaired cleft palate [ 1 case]. SATT was used as a treatment because of the absence of the required space between the middle ear cavity and the tympanic membrane to insert a TTTT. This coincides with Issam et al.[6] study in which all cases of adhesive OM [47 cases] and TM retraction [165 cases] were treated with SATT while recurrent acute OM [140 cases] and recurrent serous OM [333 cases] were treated by both TTT and SAT.

The proportion of the previous interventions with
SATTs and TTTTs was not the same. A total of $40 \%$ of patients who received a TTTT had one grommet inserted previously, $35 \%$ of patients who received SATT had one TTTT inserted previously, and $25 \%$ of patient who received TTTT had also undergone an adenoidectomy before the tube was placed and $20 \%$ of patient who received SATT had undergone adenoidectomy before the tube was placed. However, in Issam et al. [6] study, $100 \%$ of patients who received a TTTT had one TTTT inserted previously, $86.0 \%$ of patients who received SATT had one TTTT inserted previously, and $37 \%$ had also undergone an adenoidectomy before the tube was placed.

This study confirmed that SATTs can be functional for a mean of 14 months [range, 11-19 months] vs 8 months [range, $4-13$ months] for TTTTs. The result of this study [as regarding duration that tubes remain in place] comes in agreement with the following studies; Issam et al. [6] who performed 4 years of follow-up of [234] SATT and [216] TTTTs. The tubes remained in place for a median of 22 months with SATT and 7 months with TTTT which is approximately the same in this study. Cloutier et al. [4] monitored the use of 316 SATTs, comparing 2 types of tubes: Goode T-tubes [firm silicone] and plain straight-shank tubes [fluoro-plastic: length, $12 \mathrm{~mm}$; diameter, $1.14 \mathrm{~mm}$ ]. The T-tubes stayed in place for an average of 23.8 months, and the fluoroplastic tubes remained for 17.8 months. The differences may be due to the nature of tube material. Daudia et al. [1] describe the outcomes of 57 subannular ventilation tubes. The mean duration of ventilation for tubes still in situ was 22 months [range, one to 76 months; $n=29$ ], and for tubes which extruded or were removed 23 months [range, one to 85 months; $n=28$ ]. Jensen et al. [10] described a series of 121 cases with subannular ventilation tube. The mean duration of ventilation for tubes still in situ was 25 months [range, 3 to 32 months] which is longer than in this study.

As regards postoperative mean improvement in the air-bone gap, it was better in SATT [range 13 to $16 \mathrm{~dB}$ ] than in TTTT [range 17 to $20 \mathrm{~dB}$ ]. This comes in agreement with Jensen et al. [10] where they treated 121 patients with a subannular ventilation tube, the mean improvement in the air-bone gap was $17 \mathrm{~dB}$ which is approximately the same as in the present study. 
In this study, restoring aeration of the middle ear with a ventilation tube was used to prevent ear damage and improve hearing. Most complications occurred earlier with the TTTT than with the SATT, demonstrating again the lower efficiency of the TTTT.

Regarding complication in present work, otorrhea occurred in $10 \%$ of the TTTT group and $5 \%$ of the SATT group, lumen tube blockage is more frequent with TTTTs [10\%] than with SATs [5\%], new acute $\mathrm{OM}$ is more frequent with TTTTs [4\%] than with SATs [0\%], new OME is more frequent with TTTTs [25\%] than with SATs [5\%].

Issam et al. [6] compare the efficiency of the subannular T-tube [SATT] vs that of the repetitive transtympanic tube [TTTT]. Overall complication rates were lower with SATT [otorrhea, 21.4\%; perforation, 7.7\%; plugged tube, $13.7 \%$; new acute OM, 13.7\%; new OME, 5.1\%; and cholesteatoma, 1.7\%] than with TTTT [otorrhea, 26.9\%; perforation, 5.1\%; blocked tube, 20.8\%; new acute OM, 23.1\%; new OME, 37.5\%; and cholesteatoma, 0.46\%] which is comparable to this study.

Daudia et al. [1] describe the outcomes of 57 subannular ventilation tubes. Complications included blockage [16\%], perforation after extrusion [9\%], granulation [5\%] and infection [4\%] which is nearly the same in this study as regards granulation.

Retrospective follow-up done by Jensen et al.[10] describes a series of 121 cases with a subannular ventilation tube. Complications included blockage [15\%], perforation after extrusion [9\%], granulation [3\%] and Otorrhea [7\%] which is nearly the same in this study as regards granulation and otorrhea.

Florentzson et al. [11] perform a ten-year cohort study intended to determine the expected outcome of ventilation tube treatment. Infection occurred in 53 percent of the treated ear[s] at least once; the risk for infection was higher if the indication for ventilation tube placement was recurrent acute otitis media which is more than this study.

Vlastarakos et al.[12] monitor the complications associated with tympanostomy tube insertion in 125 cases. The main complications associated with tympanostomy tube insertion were: purulent otorrhea [10-26\% of cases], myringosclerosis [39$65 \%$ of cases], segmental atrophy $[16-75 \%$ of cases], atrophic scars and pars flaccida retraction pockets [28 and $21 \%$ of operated ears respectively], tympanic membrane perforations [3\% of cases], cholesteatoma [ $1 \%$ of cases], and granulation tissue [ $5 \%$ of cases] which is the same in this study as regard to granulation and residual perforation.

Persistent perforation as a complication after spontaneous or instrumental elimination of ventilatory tubes described by Sanković and Dergenc [13] after 2907 inserted short term ventilatory tubes 25 [0.86\%] persistent perforations of the eardrum were diagnosed which is less than this study.

Results of treatment with tympanostomy tubes in children with otitis media with effusion described by Zielnik et al. [14] in 113 patients after ventilation tubes insertion, in 83 ears [73\%] developed one or more middle ear sequelae. Myringosclerosis in 47 ears [41.59\%], segmental atrophy in 19 ears [16.81\%], atrophy in 14 ears [12.38\%], dysfunction of Eustachian tube in 8 ears [7.07\%], otitis media with effusion in 7 ears [6.19\%], perforation of tympanic membrane in 6 ears [5.3\%], chronic otitis media in 2 ears [1.76\%], retraction pocket in 2 ears [1.76\%] and tympanostomy tube in the middle ear cavity in 1 ear $[0.88 \%]$ were found. No cases of cholesteatoma were found.

Even with the multiple advantages of the subannular T-tube, such as its safety without damage to the tympanic membrane, its longer duration of staying in place, and its lower rate of complications, the short-term TTTT is still the choice for the first episode of acute or serious OM. However, the SAT is generally indicated in recurrent cases of OME, adhesive $\mathrm{OM}$, and atelectatic tympanic membrane.

CONCLUSION The use of SATs for long-term middle ear ventilation is safe and more efficient than transtympanic T-Tube [TTTs] for maintaining middle ear ventilation and preventing recurrent interventions in children with less otorrhea and plugged tubes.

Financial and Non-financial Relationships and Activities of Interest

None to disclose

\section{REFERENCES}

1. Casale J, Hatcher JD. Physiology, Eustachian Tube Function. StatPearls Publishing; 2019. http://www.ncbi. nlm. nih.gov/pubmed/30335317. Accessed February 11, 2020. 
2. Alicandri-Ciufelli M, Marchioni D, Pavesi G, Canzano F, Feletti A, Presutti L. Acquisition of surgical skills for endoscopic ear and lateral skull base surgery: A staged training programme. Acta Otorhinolaryngol Ital. 2018;38[2]:151-159. [DOI:10.14639/0392-100X-1878].

3. Jassar P, Coatesworth A, Strachan DR. Long-term ventilation of the middle ear using a sub-annular tympanotomy technique: A follow-up study. J Laryngol Otol. 2004; 118 [12]: 933-936. [DOI: 10.1258/ 0022215042790510].

4. Yang $\mathbf{N}$, Beaudoin PL, Nguyen M, Maillé $H$, Maniakas A, Saliba I. Subannular ventilation tubes in the pediatric population: Clinical outcomes of over 1000 insertions. Int J Pediatr Otorhinolaryngol. 2020; 131: 109859. [DOI: 10.1016/j.jporl.2020.109859].

5. Martin-Hirsch DP, Woodhead CJ, Vize CE. Long-term ventilation of the middle ear using a tympanotomy technique. J Laryngol Otol. 1995; 109 [12]: 1151-1154. [DOI: 10.1017/s002221510013230x]

6. Saliba I, Boutin T, Arcand P, Froehlich P, Abela A. Advantages of subannular tube vs repetitive transtympanic tube technique. Arch Otolaryngol - Head Neck Surg. 2011;137[12]:1210-1216. [DOI: 10.1001/archoto. 2011.197].

7. Rosenfeld RM, Shin JJ, Schwartz SR, Coggins R, Gagnon L, Hackell JM, et al. Clinical Practice Guideline: Otitis Media with Effusion [Update]. Otolaryngol Head Neck Surg. 2016;154[1_suppl]:S1S41. [DOI:10.1177/0194599815623467].

8. Zou Y, Huang D, Hu B, Zhai S, Fang Y. [The role of fibrinolysis in pathogenesis of middle ears adhesions]. Zhonghua Er Bi Yan Hou Ke Za Zhi. 2001;36[5]:357359. [PMID: 12761944]. [Article in Chinese; English abstract].
9. Selvan VS, Karuppasamy C. A comprehensive study on cartilage tympanoplasty in adhesive otitis media. Int $\mathrm{J}$ Otorhinolaryngol Head Neck Surg. 2017;3[3]:650. [DOI:10.18203/issn.2454-5929.ijohns20173041]

10. Daudia A, Yelavich S, Dawes PJD. Long-term middle-ear ventilation with subannular tubes. J Laryngol Otol. 2010; 124 [9]: 945 - 949. [DOI: 10.1017/S00222 15110000897]

11. Florentzson R, Finizia $\mathbf{C}$. Transmyringeal ventilation tube treatment: A 10-year cohort study. Int J Pediatr Otorhinolaryngol. 2012;76[8]:1117-1122. [DOI: 10.1016/ j.ijporl. 2012.04.013]

12. Vanneste $\mathbf{P}$, Page $\mathbf{C}$. Otitis media with effusion in children: Pathophysiology, diagnosis, and treatment. A review. J Otol. 2019;14[2]:33-39. [DOI: 10.1016/j.joto. 2019. 01.005]

13. Sanković S, Dergenc R. [Surgical treatment of secretory otitis media: persistent perforation as a rare complication]. Srp Arh Celok Lek. 1999; 127[1-2]:3234. [Article in Serbian; English abstract] [PMID: 10377838].

14. Zielnik-Jurkiewicz B, Olszewska-Sosińska $\quad$, Rakowska M. [Results of treatment with tympanostomy tubes in children with otitis media with effusion]. Otolaryngol Pol. 2006;60[2]:181-185. [Article in Polish; English abstract] [PMID:16903334] 